\title{
UM ESTUDO SOBRE O PERFIL DOS EMPREGADOS COM DEFICIÊNCIA EM UMA ORGANIZAÇÃO
}

\author{
A STUDY ON THE PROFILE OF DISABLED EMPLOYEES IN AN ORGANIZATION
}

\author{
Ana Cristina Cypriano PEREIRA ${ }^{1}$ \\ Liliana PASSERINO²
}

\begin{abstract}
RESUMO: Baseado na premissa de que todo processo inclusivo, seja este educacional, social ou laboral, precisa partir de uma apropriação do contexto sociocultural dos diferentes atores envolvidos - no caso desta pesquisa: empregadores, pessoas com deficiência e empresa, o presente estudo tem como objetivo identificar o perfil dos empregados com deficiência em uma organização de grande porte do ramo da alimentação. Procuramos discutir o contexto social no qual os trabalhadores com deficiência estão inseridos através de um recorte quantitativo dos resultados de uma pesquisa desenvolvida sobre o processo de inclusão em uma organização. O estudo foi desenvolvido por meio dos documentos disponibilizados pela empresa, bem como de documentos nacionais. Os resultados revelam uma cartografia das pessoas com deficiência inseridas na organização através de informações sobre escolaridade, idade, salário, funções e tipos de deficiência, comparando-os aos dados nacionais disponíveis sobre as pessoas com deficiência. Por fim, discutimos alguns resultados obtidos com o estudo. Em que pese a importância das políticas públicas, propomos uma reflexão acerca de mecanismos como o Benefício da Prestação Continuada (BPC), para o favorecimento desta relação entre trabalho e deficiência. Entendemos, finalmente, que é urgente educar e qualificar as pessoas com deficiência, mas não é suficiente, pois também são necessárias ações estruturantes da sociedade para o sucesso do processo de inclusão.
\end{abstract}

PALAVRAS-CHAVE: Pessoas com deficiência. Inclusão social. Profissionalização do deficiente.

\begin{abstract}
: based on the premise that all inclusive processes, be they educational, social or occupational, require an appropriation of the sociocultural context of the different actors involved - in the case of this research: employers, disabled people and company, the aim of this study is to identify the profile of employees with disabilities in a large food industry company. We attempted to discuss the social context in which workers with disabilities are part of the work force by looking at a sample of the quantitative results of a survey conducted on the inclusion process in an organization. Documents provided by the company were analyzed, as were national policies. The results revealed a cartography of people with disabilities included in the organization based on data on education, age, salary, duties and types of disabilities, which were then compared to national data on people with disabilities. We discussed some results obtained during the study. Despite the importance of public policies, we propose a reflection on mechanisms such as the Benefício da Prestação Continuada (BPC) for encouraging positive relations between work and disability. Finally, we believe that promoting education and skills for people with disabled people is essential, though not sufficient. Society must also provide for structured actions in order to assure success in the process of inclusion.
\end{abstract}

KEYWORDS: People with Disabilities. Inclusion. Professional qualification.

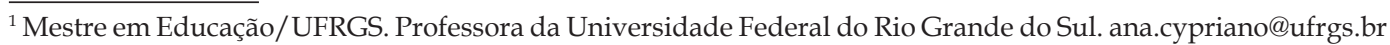

${ }^{2}$ Doutora em Informática na Educação/UFRGS. Pesquisadora em Informática na Educação Especial e professora da Faculdade de Educação/UFRGS. liliana@cinted.ufrgs.br
} 


\section{INTRODUÇÃo}

A inclusão de pessoas com deficiência no mercado de trabalho ainda é um fenômeno complexo e heterogêneo, no qual participam diversas variáveis, em alguns casos conflitantes, resultado, em parte, das contradições do sistema capitalista e, em outras, da própria complexidade dos seres humanos e dos sistemas sociais por eles estruturados. Um dos aspectos muitas vezes mencionado em pesquisas que abordam as dificuldades de inserção laboral no mercado de trabalho é o educacional (LANCILLOTTI, 2003; TANAKA; MANZINI, 2005; NASCIMENTO; MIRANDA, 2007; GÖDKE, 2010), já que “a educação e o encaminhamento para o mercado ocorrem a partir das demandas do capital e nos seus limites" (LANCILLOTTI, 2003, p. 17).

Por mais que se discuta a questão da ideologia, que segundo Santos (1995) não deveria impedir o processo de integração das pessoas com deficiência, Lancillotti (2003) alerta que, embora crítica, esta discussão deve ser permeada pelos limites e contradições da sociedade capitalista, já que o movimento do capital é essencialmente excludente.

O presente trabalho se embasa na premissa de que todo processo inclusivo, seja este educacional, social ou laboral precisa partir de uma apropriação do contexto sociocultural dos diferentes atores envolvidos (empregadores, pessoas com deficiência e empresa). Ao caracterizarmos os indivíduos que compõem a organização onde foi desenvolvida a presente investigação, com o objetivo de identificar o perfil dos empregados com deficiência na organização em estudo, procuramos discutir o contexto social no qual estão inseridos. Para tanto, apresentamos a seguir um recorte quantitativo de resultados de uma pesquisa desenvolvida sobre o processo de inclusão numa organização de grande porte.

Além disso, pretende-se contribuir com a construção de uma cartografia deste perfil, através de um exame comparativo com dados nacionais, o que permite a análise e a interpretação das possíveis dificuldades advindas dos processos educacionais e sociais para a inclusão no mercado de trabalho.

Por último, consideramos que empresas e empregados são atores num sistema social mais amplo - a nação - e grande parte das características ora apresentadas resulta das políticas públicas exaustivamente analisadas por diversos autores, tais como Pastore (2000), Oliveira Goulart Junior e Fernandes (2009), Mendonça (2010), os quais de forma geral consideram tais políticas ainda pouco eficientes para os objetivos aos quais se propõem. Assim, este estudo sobre o perfil das pessoas com deficiência em uma organização oferece subsídios à reflexão acerca desta problemática social enquanto processo, e é fundamental para desestimular a prevalência da lei sobre as ações estruturantes da sociedade.

Procuramos, portanto, avançar no processo de análise da situação e inserção laboral das pessoas com deficiência, pois, se anteriormente Tanaka e Manzini (2005) já nos apresentaram "o que os empregadores pensam sobre o trabalho da pessoa com deficiência", nos propomos a conhecer tais pessoas com 
deficiência no contexto do trabalho, processo complementar e essencial para a reflexão social ora proposta.

\section{Metodologia}

Consideramos aqui o método como elemento essencial para se estudar o homem como unidade biológica e como ser social, participante de um processo histórico, no qual, enquanto sujeito, está assinalado e inserido na cultura através da qual produz e reproduz a realidade social e é produzido e reproduzido por ela (FREITAS, 2002).

No presente artigo, destacamos uma pesquisa desenvolvida a partir de um recorte que tem por finalidade caracterizar as pessoas com deficiência de uma organização ${ }^{3}$. A pesquisa foi realizada no âmbito de uma organização de grande porte, do ramo da alimentação, ativa em todo o território nacional e representada no sul do Brasil, onde a pesquisa se desenvolveu. A escolha desta empresa foi motivada por se tratar de uma organização que se enquadra nas premissas da Lei de Cotas e que apresentava dificuldades na inserção profissional de pessoas com deficiência ${ }^{4}$. A organização está classificada como empresa de grande porte ${ }^{5}$, segundo os critérios do IBGE. Por possuir acima de 1001 funcionários, para cumprir sua cota estipulada no Artigo 93 da Lei 8.213 de 1991 (BRASIL, 2004a), de $5 \%$ de pessoas com deficiência, é necessário um incremento de 395\% sobre os funcionários com deficiência já contratados. No momento do estudo, o número de deficientes representava 1,01\% do montante de funcionários da organização, muito aquém do estipulado em Lei e desejado pela organização.

O estudo foi desenvolvido através dos dados coletados e documentos disponibilizados pela empresa e os sujeitos com deficiência nela empregados. Tratase de arquivo particular de instituição privada, disponibilizado por meio digital pelo Setor de Recursos Humanos, que se refere à totalidade dos funcionários com deficiência da organização. Além disso, foram utilizados documentos nacionais oficiais que subsidiaram o confronto e análise dos dados. Os documentos internos constituem, segundo Marconi e Lakatos (1996), fontes primárias de pesquisa e apresentam informações que auxiliam a compreensão do universo da pesquisa.

Após a coleta, os dados foram organizados em categorias, tabulados e analisados estatisticamente, e confrontados com os indicadores nacionais com a finalidade de satisfação do objetivo proposto (GIL, 2007).

\footnotetext{
${ }^{3}$ O presente artigo é parte da dissertação de mestrado em Educação da Universidade Federal do Rio Grande do Sul, intitulada "Inclusão de Pessoas com Deficiência no Trabalho e o movimento da Cultura Organizacional: análise multifacetada de uma organização".

${ }^{4}$ As informações da Organização serão preservadas, pois estão protegidas por cláusula de sigilo em Termo de Cooperação de Pesquisa firmado entre a instituição e as autoras. Desta forma, a empresa será descrita na medida necessária ao entendimento do contexto do estudo ora apresentado.

${ }^{5}$ Segundo o IBGE, o critério de classificação do porte das empresas, para fins bancários, ações de tecnologia, exportação e outros, relacionam-se ao número de funcionários. Sendo, na indústria, classificados como grande as empresas com mais de 500 funcionários. Disponível em http://www.sebrae-sc.com.br/leis/default. asp?vcdtexto=4154. Acesso em: 25 nov. 2010.
} 


\section{Resultados E discussão}

A partir da análise dos documentos obtidos na organização, apresentamos a seguir os dados referentes aos trabalhadores com deficiência da Organização:

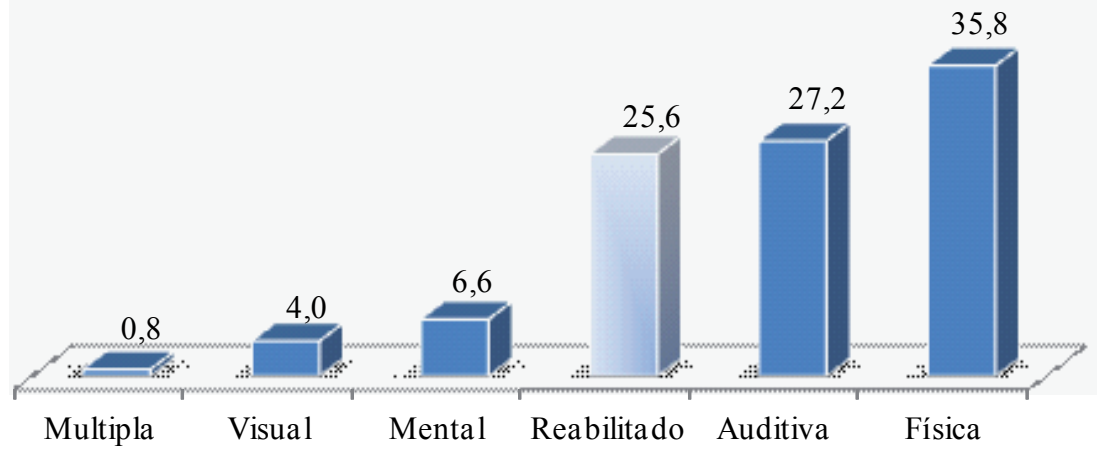

Figura 1 - Distribuição dos Tipos de Deficiência presentes na Empresa (em \%) Fonte: Dados obtidos da Organização

A Figura 1 expressa que, dentre os trabalhadores empregados pela organização pesquisada, a maioria é de pessoas com deficiência física. Esta tendência é observada desde a década de 60 , quando o pós-guerra consolidou a necessidade de inserção dos deficientes oriundos deste momento histórico (LANCILLOTI, 2003).

Outros estudos também apontam a deficiência física como a deficiência que tem prevalência em ocupação de vagas no mercado de trabalho (LANCILLOTI, 2003), juntamente com a deficiência auditiva (GÖDKE, 2010), dependendo em grande parte do setor produtivo analisado, da região onde se realiza o estudo, entre outros fatores. Por outro lado, a deficiência múltipla, que aparece em menor participação na organização estudada, igualmente revela-se de forma pouco significativa em outras pesquisas (LANCILLOTI, 2003; GÖDKE, 2010).

Para Lancillotti (2003) este fenômeno está relacionado ao acesso da pessoa com deficiência à escola: mesmo que o sujeito com deficiência física enfrente barreiras para frequentar as instituições escolares - geralmente barreiras arquitetônicas comparativamente a outras deficiências, este grupo tem vantagens sobre os demais no quesito escolarização - tão importante para alcançar o mercado de trabalho.

Outro fator pontuado pela autora refere-se à ocupação de funções administrativas por este grupo de pessoas com deficiência (LANCILLOTTI, 2003). Neste caso, estão relacionados não só a escolaridade, mas também os avanços 
tecnológicos (recursos de tecnologia assistiva ${ }^{6}$ ) e ergonômicos, cada vez mais presentes na sociedade e no mercado de trabalho.

A menor prevalência de empregados com deficiência mental e deficiência múltipla também tem relação a fatos que suscitam questões do diagnóstico, do baixo grau de escolaridade e do desconhecimento, que remete ao senso comum como fator estigmatizante à contratação (LANCILLOTTI, 2003). Mendonça (2010) acrescenta que, ainda que a baixa escolaridade esteja associada às pessoas com deficiência mental, por vezes esta pode ser apenas uma escusa que justifica a necessidade do capital de manter-se competitivo na esfera produtiva. No entender deste autor, as empresas entendem que este tipo de deficiência representa possibilidades exponenciais de menor produtividade (MENDONÇA, 2010).

Tanaka e Manzini (2005) corroboram as afirmativas sobre as dificuldades de acesso e permanência da pessoa com deficiência no mercado de trabalho, apontando fatores que precisam ser analisados para a inserção efetiva dessas pessoas: "preparo profissional e social da pessoa com deficiência [...] e também as condições estruturais, funcionais e sociais do ambiente que irá recebê-la" (p. 276).

Para além da análise do perfil destes trabalhadores na empresa em estudo, é importante comparar a realidade da deficiência no Brasil (em números percentuais) à realidade da organização. ${ }^{7}$

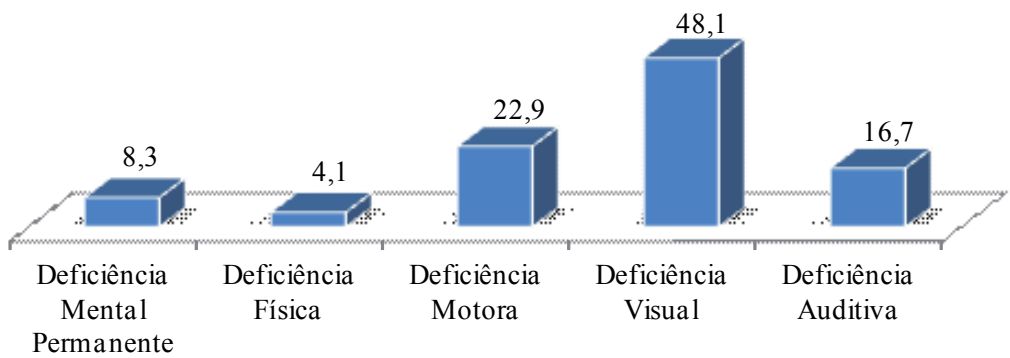

Figura 2 - População Brasileira por tipo de deficiência (em \%).

Fonte: Dados do IBGE, Censo Demográfico 2000 (IBGE, 2000).

\footnotetext{
${ }^{6}$ Segundo o Comitê de Ajudas Técnicas (CAT), tecnologia assistiva "é uma área do conhecimento, de característica interdisciplinar, que engloba produtos, recursos, metodologias, estratégias, práticas e serviços que objetivam promover a funcionalidade, relacionada à atividade e participação, de pessoas com deficiência, incapacidades ou mobilidade reduzida, visando sua autonomia, independência, qualidade de vida e inclusão social" (BRASIL, 2007). Referimo-nos neste estudo aos recursos e serviços de tecnologia assistiva para ampliação ou possível realização das atividades necessárias e intencionadas pelas pessoas com deficiência. Disponível em: http://www.mj.gov.br/ corde/arquivos/doc/Ata_VII_Reunião_do_Comite_de_Ajudas_Técnicas.doc. Acesso em: 05 jan. 2011.

7 Embora as visitas tenham se concentrado em dois Estados da Federação, os dados quantitativos apresentados nesta pesquisa referem-se à totalidade da Empresa, que atua em todo o Brasil, motivo pelo qual se realiza um comparativo Nacional e não Estadual (RS).
} 
A Figura 2 apresenta os dados da população brasileira com deficiência, segundo padrões definidos pelo IBGE IB. $^{8}$.

[...] Esta estratégia de investigar a existência de deficiência ou incapacidade foi definida com a Coordenadoria Nacional para Integração da Pessoa Portadora de Deficiência - CORDE do Ministério da Justiça, em trabalho conjunto desde a fase de planejamento do Censo Demográfico 2000 (IBGE, 2000, p. 30).

Os padrões ou estratégias definidas pelo IBGE levantam se a pessoa tem deficiência mental permanente ou deficiência física permanente, como tetraplegia, paraplegia, hemiplegia, falta de membro ou de parte dele. O instituto apontou também as pessoas com deficiência auditiva, visual e motora por meio da avaliação do seu grau de incapacidade (incapaz, com grande dificuldade ou com alguma dificuldade permanente, sem nenhuma dificuldade) de enxergar, ouvir e caminhar ou subir escada. Ainda, "[...] não se considerou como deficiência mental as perturbações ou doenças mentais como autismo, neurose, esquizofrenia e psicose" (IBGE, 2000). É importante ressaltar que as respostas da coleta de informações realizada por este Instituto são autodeclaratórias, a despeito de qualquer juízo do recenseador.

Em sendo assim, sabe-se que os critérios de definição da população brasileira por tipo de deficiência, ilustrados pela Figura 2, apresentam uma realidade de difícil comparação com os dados das pessoas com deficiência empregadas nas organizações, mais especificamente na organização estudada.

Neste caso, identificamos, sobretudo, a problemática da metodologia autodeclaratória adotada pelo Instituto Brasileiro de Geografia e Estatística. Aparentemente, esta metodologia cria um distanciamento entre a realidade da população com deficiência, apontada pelo documento do IBGE, e a realidade evidenciada pelas organizações, uma vez que não segue as mesmas exigências de diagnóstico e registro do Decreto n 5.296 de 2004 (BRASIL, 2004b). Para inclusão das pessoas com deficiência nas cotas estipuladas em lei, é necessário um apanhado de documentos que comprovem que o sujeito atende aos critérios estabelecidos na legislação.

\footnotetext{
8 Na data de conclusão do estudo os dados do Censo do IBGE 2010 ainda não estavam disponíveis. Para este artigo mantivemos as informações do Censo de 2000, os quais subsidiaram a presente pesquisa.
} 


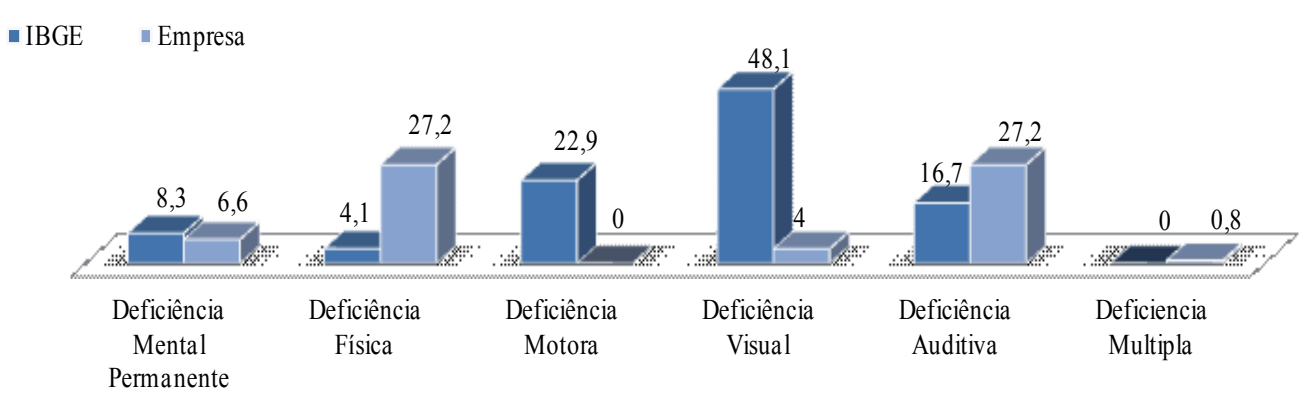

Figura 3 - Comparação entre os Tipos de Deficiência presentes na Empresa e População Brasileira (em \%)

Fonte: Dados do IBGE, Censo Demográfico 2000 e Dados obtidos da Organização

* Não há correlação nos registros das duas deficiências assinaladas, isto é, a deficiência motora não é registrada pela empresa, uma vez que não consta na previsão legal do Decreto 5.296 de 2004 e a Deficiência Múltipla não fez parte dos registros do IBGE.

Feitas as devidas ressalvas, comparamos os dados da organização estudada e o censo demográfico do IBGE. Na Figura 3, observa-se que, apesar de a deficiência visual ter grande prevalência populacional $(48,1 \%)$, é o segundo menor grupo registrado, apenas $4 \%$ das pessoas com deficiência empregadas pela empresa têm deficiência visual. Por outro lado, a deficiência física, que apresenta o segundo menor registro populacional pelo IBGE, é, ao contrário, a deficiência que apresenta maior número de contratações na contagem da empresa.

Em relação à escolaridade, os dados do IBGE (2000) destacam que, conquanto a frequência escolar das pessoas de sete a 14 anos estivesse praticamente universalizada (93,5\%), este percentual caía para $88,6 \%$ em se tratando de pessoas com deficiência, para $74,9 \%$ no caso de deficiências severas e, entre as pessoas com deficiência física permanente, o Instituto observou a menor taxa de frequência escolar, correspondente a $61 \%$.

[...] A partir da alfabetização a participação da PPDs no total das matrículas vai decrescendo, pois dentre os matriculados na alfabetização no ano 2001, cerca de 4,4\% eram PPDs, enquanto que esse número decresce significativamente para o ensino fundamental $(0,6 \%)$ e ensino médio $(0 \%)$. Tal resultado acaba refletindo as dificuldades que as PPDs têm para ampliar seu grau de instrução (NERI, 2003, p. 24). 


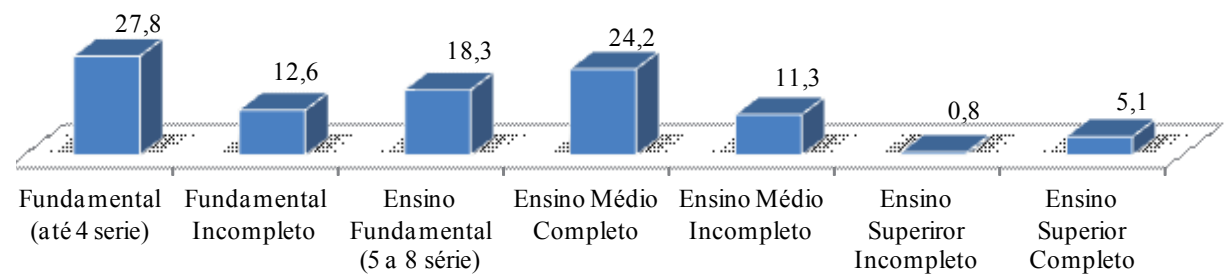

Figura 4 - Escolaridade dos Funcionários com deficiência na Empresa (em \% $)^{9}$ Fonte: Dados obtidos da Organização

O Gráfico da Figura 4 revela uma realidade ainda carente em relação à escolaridade das pessoas com deficiência. Dentre as pessoas contratadas pela Organização, cerca de 5\% têm ensino superior completo, podendo ocupar vagas mais qualificadas na hierarquia funcional. Apenas $24,2 \%$ dos funcionários possuem ensino médio completo.

Entre as menores qualificações apontadas pela empresa - essenciais para o desempenho de qualquer atividade - registra-se 11,3\% de funcionários com ensino médio incompleto e 18,3\% com Ensino Fundamental - até a $8^{a}$ serie. Aparentemente o acesso e permanência das pessoas com deficiência no ensino, principalmente no ensino superior, parece ser uma carência da sociedade atual.

Em sua pesquisa, Gödke (2010), ao entrevistar nove empresas de grande porte de Curitiba e Região Metropolitana, encontrou números que corroboram esta afirmativa quanto a esta precária escolarização das pessoas com deficiência: dos funcionários com deficiência empregados nestas indústrias, $13 \%$ dos deficientes possuíam ensino médio e $87 \%$ ensino fundamental.

Tabela 1 - Distribuição da Escolaridade por Tipo de Deficiência em (\%)

\begin{tabular}{|c|c|c|c|c|c|c|c|c|c|}
\hline \multirow{2}{*}{ Deficiência } & \multicolumn{7}{|c|}{ Escolaridade (em \%) } \\
\cline { 2 - 12 } & \multirow{2}{*}{ Analfabeto } & EF & EF 4 série & EF 4 série $^{\text {EF 5 a }}$ & EM & EM & ES & ES \\
\hline completo & completo & incompleto & $8^{\text {a }}$ série & completo & incompleto & completo & incompleto \\
\hline Fúsica & 0,6 & 13,9 & 12,2 & 7,8 & 16,7 & 29,4 & 10 & 8,9 & 0,6 \\
\hline Mental & 8,8 & 11,8 & 5,9 & 29,4 & 23,5 & 11,8 & 5,9 & - & 2,9 \\
\hline Múltipla & - & - & 50 & - & 25 & 25 & - & - & - \\
\hline Reabilitado & - & 31,7 & 16,7 & 4 & 24,6 & 17,5 & 4,8 & - & 0,8 \\
\hline Visual & 4,5 & 22,7 & 9,1 & 4,5 & 9,1 & 27,3 & 18,2 & 4,5 & - \\
\hline
\end{tabular}

Fonte: Dados obtidos na Organização

\footnotetext{
${ }_{9}^{9}$ O gráfico sobre escolaridade dos funcionários deficientes na empresa (Figura 4) foi construído considerando o universo de $74,4 \%$ de deficientes declarados na empresa, isto é, não foram computados para esta análise as pessoas Reabilitadas constantes no gráfico da Figura 1.
} 
$\mathrm{Na}$ análise que relaciona a escolaridade dos funcionários da Organização por tipo de deficiência (Tabela 1), novamente revelam-se como grupo com maior escolaridade de nível superior as pessoas com deficiência física, tendo como causas prováveis as já mencionadas neste artigo. Entre a mais baixa escolaridade registrada - EF $4^{\mathrm{a}}$ série incompleto - a deficiência mental se sobressai, evidenciando o estigma social sobre estes, as limitações da própria deficiência, assim como a questão do acesso à educação. Este dado nos induz à análise de que a grande discriminação sofrida por este grupo, como afirma Goffman (1988), o conduz ao isolamento, convivendo apenas com seus iguais ou com quem o aceite e compreenda - geralmente a família - mesmo que, para tanto, tenham tido que abrir mão da escola, da educação e do trabalho.

A grande concentração percentual da escolaridade das pessoas com deficiência encontra-se no ensino fundamental de $5^{\mathrm{a}}$ a $8^{\mathrm{a}}$ séries e ensino médio, demonstrando o esforço que o campo da educação tem realizado nos últimos anos.

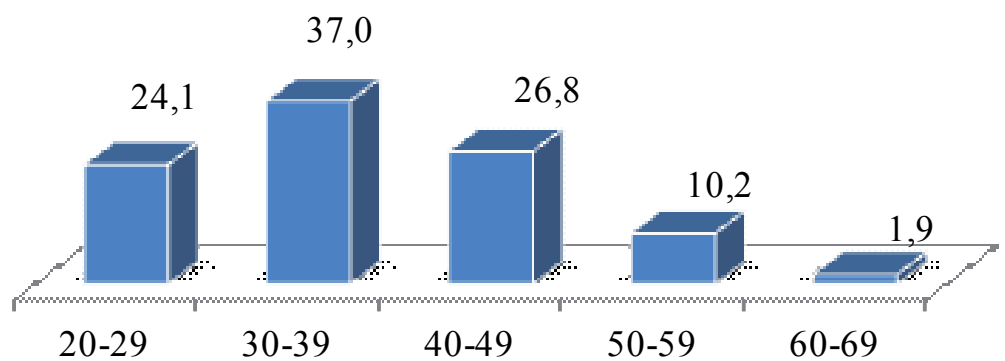

Figura 5 - Distribuição das Idades dos Funcionários com Deficiência na Empresa (em \%)

Fonte: Dados obtidos da Organização

O gráfico da Figura 5 revela-nos uma aproximação entre os dados da Escolaridade dos Funcionários com o movimento de mudança da educação brasileira. Os funcionários com mais idade provavelmente foram os que mais tiveram dificuldade de acesso à educação. Por outro lado, há um relativo equilíbrio entre o percentual de funcionários entre 20 e 29 anos (24\%) e aqueles que conseguiram ingressar no ensino médio, concluindo-o ou não (35\%). Mesmo que a relação entre os gráficos das duas figuras não seja linear, há uma aproximação dos seus dados à realidade da educação observada nos últimos anos no país, já que, a partir de 1996, a Lei de Diretrizes de Bases da Educação Nacional (BRASIL, 2004c) garante não só acesso à educação pelas pessoas com deficiência, como também, finalmente, indica a rede regular de ensino como opção preferencial de assento deste alunado.

Em contrapartida, os sujeitos com idade superior a 40 anos representam apenas 39\% das pessoas com deficiência empregadas na organização. Entre outras possibilidades de interpretação, entendemos que este número nos remete à dificuldade de acesso à educação enfrentada por estes indivíduos, bem como à 
inexistência da obrigatoriedade de contratação imposta pela Lei de Cotas. Além disso, a educação praticada no passado era geralmente muito mais assistencialista e médica e menos educacional ${ }^{10}$.

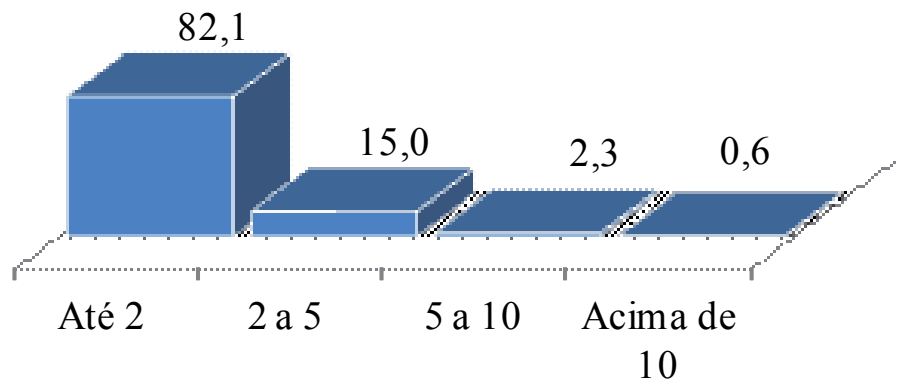

Figura 6 - Distribuição Salarial dos Funcionários com deficiência na Empresa por salário mínimo (em \%)

Fonte: Dados obtidos da Organização

Em relação à remuneração percebida pelos funcionários com deficiência Figura 6 -, apenas $1 \%$ das pessoas contratadas recebe acima de 10 salários mínimos. No estrato que compreende de 5 a 10 salários estão apenas 2\% dos funcionários. Entre os salários mais baixos, até dois salários e de dois a cinco, estão concentrados respectivamente 82 e 15\% dos funcionários. Desta forma, 97\% dos funcionários recebem até cinco salários mínimos.

Os dados disponíveis não nos permitam fazer uma correlação direta entre a escolaridade dos funcionários e a sua remuneração. O baixo índice de funcionários com escolaridade superior e de remuneração acima de cinco salários mínimos estão relacionados de forma bastante estreita. Da mesma forma, aparentemente também se observa correlação, mas neste caso inversa, entre a baixa escolaridade e a significativa participação dos que recebem remuneração de até dois salários mínimos.

Este retrato parece muito difícil de ser solucionado pelas empresas, pois é na base educacional que residem os maiores entraves ora apresentados.

Aparentemente, este cenário conduz, consequentemente, à dificuldade de contratação das pessoas com deficiência - um dos principais argumentos das empresas. A equação da baixa qualificação e baixos salários induz a uma tendência de que seria mais interessante as pessoas com deficiência e suas famílias continuar

\footnotetext{
10 Apenas após o Parecer do CNE/CEB (Conselho Nacional de Educação/Câmara de Educação Básica) $\mathrm{n}^{\circ}$ 17/2001, Instituições como a APAE começaram a avaliar e diplomar seus alunos de acordo com as diretrizes estabelecidas na Política de Educação Brasileira. Antes disto, o caráter destas Instituições eram muito mais assistencialistas do que formativas. Disponível em http://portal.mec.gov.br/cne/arquivos/pdf/CEB017_2001.pdf. Acesso em: 14 dez. 2010.
} 
recebendo o Beneficio Social $(\mathrm{BPC})^{11}$, ao invés de "arriscar-se" com as inseguranças e dificuldades de trabalhar.

Neste particular, não se quer julgar a pessoa com deficiência e seu familiar que optam em não trabalhar, ao contrário, cabe aqui discutir os motivos que os conduzem a esta opção, o que faz com que as pessoas com deficiência prefiram não trabalhar por esta parca remuneração. Inicialmente, o medo pelo desconhecido e a superproteção familiar podem ser responsáveis por parte desta decisão. O exercício do labor também toma o tempo dedicado por muitos sujeitos a terapias e oficinas de reabilitação, responsáveis, por certo, pelo seu bem-estar e conforto físico.

Contudo, talvez o empecilho mais premente neste processo seja a dificuldade de transporte - uma dolorosa barreira das cidades brasileiras. $\mathrm{Na}$ publicação Sem Limite (IBDD, 2003), depoimentos de pessoas com deficiência dão a dimensão desta dificuldade, e esta problemática pode ser ainda mais complexa, reunindo o difícil acesso ao transporte ao preconceito estrutural, o estigma social e o desrespeito presentes em nossa sociedade.

[...] Eu saí às cinco da tarde e fiquei até dez horas da noite no ponto. Eu fazia sinal para o ônibus e o motorista abria a porta, mas eu não conseguia entrar com medo de as pessoas me olharem, com medo da discriminação. Entrar no ônibus pela frente já chama a atenção, subir de muletas, pior ainda. Até hoje você choca as pessoas quando entra pela porta da frente [...]. Muitas vezes, encontrei alguém sentado no banco reservado para deficientes e tive que brigar para sentar ali. - Relato de Hermes da Fonseca Lopes Junior (IBDD, 2003, p.57).

No que se refere a esta questão ainda, o nível socioeconômico no contexto familiar destes indivíduos deve ser elemento levado em consideração. Segundo documento do Banco Mundial, cerca de $82 \%$ das pessoas com deficiência na America Latina e Caribe vivem na pobreza:

[...] En América Latina y el Caribe, unos 50 millones de personas, aproximadamente el 10 por ciento de la población, tienen alguna discapacidad. Alrededor de un 82 por ciento de ellas vive en la pobreza, menos del 20 por ciento cuenta con seguro médico, y solamente entre el 20 y 30 por ciento de los niños con discapacidades asiste a la escuela (BIRD, 2004).

Pode-se inferir que esta constatação do Banco Mundial de fato estende-se ao Brasil, uma vez que, em relação Índice de Desenvolvimento Humano (IDH), o Brasil está situado entre os de alto desenvolvimento humano e é maior que a média

\footnotetext{
11 O Benefício da Prestação Continuada (BPC) é um direito garantido pela Constituição Federal de 1988 e consiste no pagamento de um salário mínimo mensal a pessoas com 65 anos de idade ou mais e a pessoas com deficiência incapacitante para a vida independente e para o trabalho. Em ambos os casos a renda per capita familiar deve ser inferior a 1/4 do salário mínimo. O BPC encontra amparo legal na Lei 10.741, de $1^{\circ}$ de outubro de 2003, que institui o Estatuto do Idoso. O benefício é gerido pelo Ministério do Desenvolvimento Social e Combate à Fome (MDS), a quem compete sua gestão, acompanhamento e avaliação. Ao Instituto Nacional do Seguro Social (INSS), compete a sua operacionalização. Os recursos para custeio do BPC provêm do Fundo Nacional de Assistência Social (FNAS). Em 2008, mais de 1,4 milhão de benefícios foram destinados as pessoas com deficiência. Informações disponíveis em http://www.mds.gov.br/programas/rede-suas/protecao-social-basica/beneficio-de-prestacaocontinuada-bpc. Acesso em: 2 mar. 2010.
} 
mundial $(0,624)$, mas, segundo o Relatório do Programa para Desenvolvimento Humano (PNUD, 2010), é parecido com o do conjunto dos países da América Latina e Caribe $(0,704)$, ocupando o $73^{\circ}$ lugar no ranking de 169 nações e territórios. O índice brasileiro é de 0,699, de acordo com este Relatório. Neri (2003) afirma ainda que é comum, de forma geral, para o contingente de pessoas com deficiência, que essa condição traga consigo a pobreza, a segregação, a indiferença, a desigualdade de oportunidades e a exclusão.

Desta maneira, compreende-se que o rendimento percebido através do BPC seja realmente importante para esta parcela da população, ainda tão carente de medidas sociais de inclusão.

Naturalmente, não se pretende encerrar esta questão, tampouco justificar e muito menos condenar uma ou outra posição. O que não se pode, entretanto, é calar-se para este debate que urge em sociedade. É imperiosa a discussão envolvendo o nível governamental (no que se refere às políticas sociais e à infraestrutura), as comunidades de pessoas com deficiência (para sua manifestação e seu posicionamento) e também as empresas - para além das críticas, urge sua participação e colaboração neste importante debate, incluindo a crítica ao caráter assistencialista do BPC.

Não se pode negar que a política social que instaurou o BPC tinha o objetivo de atender aos direitos de cidadania das pessoas pobres com deficiência que necessitam de assistência social, uma vez que apenas a política de inclusão no mercado de trabalho não promoveria a inclusão social (SANTOS, 2011). Segundo o autor, em sua pesquisa, "das pessoas deficientes entrevistadas, todas reportaram melhoria significativa em suas condições de vida após o recebimento do BPC" (p. 791). Contudo, ainda assim, revelam-se como políticas explicitamente antagônicas na origem de suas concepções.

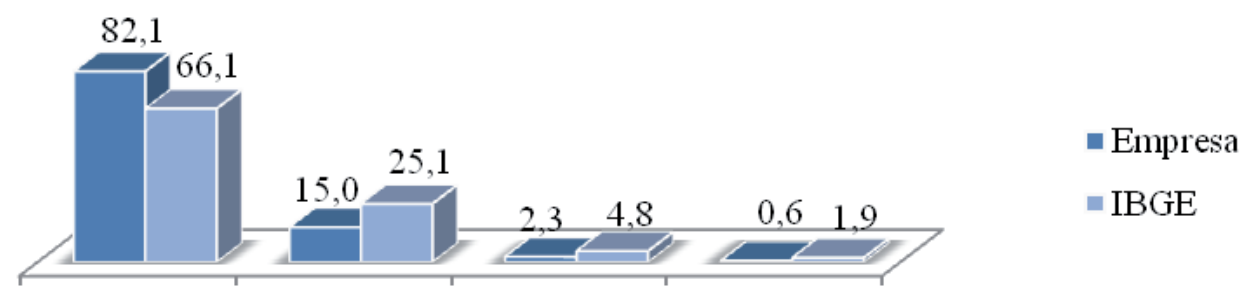

Até $2 \quad 2$ a $5 \quad 5$ a $10 \quad$ Acima de 10

Figura 7 - Comparação entre a Distribuição Salarial dos Funcionários Deficientes na Empresa por salário mínimo e o Rendimento Mensal da População acima de 10 anos com carteira assinada (em \%)

Fonte: Dados do IBGE, Censo Demográfico 2000 e Dados obtidos da Organização 
Ainda em relação à remuneração, a Figura $7^{12}$ faz uma correlação entre a distribuição salarial dos funcionários da organização pesquisada e a realidade brasileira, através do Censo Demográfico 2000. Segundo a Figura, podemos observar que na empresa há $16 \%$ a mais de empregados com deficiência recebendo até dois salários mínimos, em relação à proporção brasileira no mesmo intervalo. Apesar de serem menos significativos, os dados do IBGE, nos intervalos de cinco a 10 e mais de 10 salários, representam maior participação quando comparados aos da Empresa.

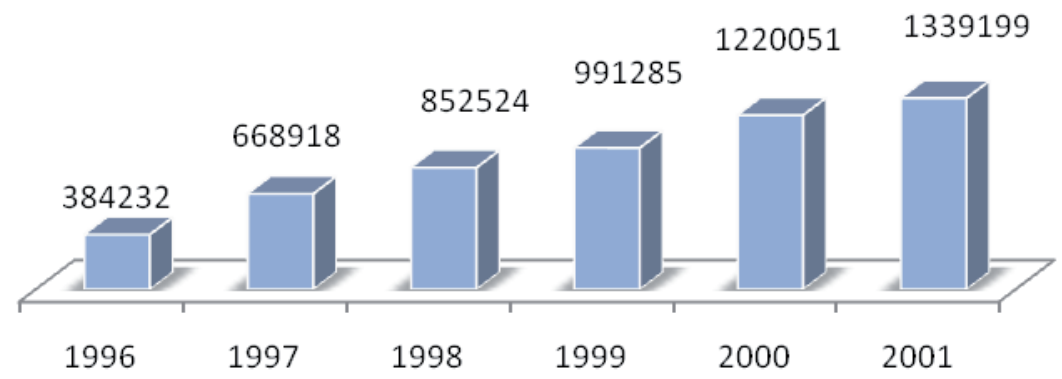

Figura 8 - Número de Benefícios da Prestação Continuada concedidos a PPDs 1996 a 2001.

Fonte: SEAS 2001 (apud NERI, 2003)

Assim, se levarmos em conta o incremento das políticas assistenciais nos últimos anos, demonstrado na Figura 8, no que se refere ao pagamento do BPC, além da remuneração percebida pelas pessoas com deficiência - apresentada pela Figura 7, talvez estejamos próximos ao entendimento de um fenômeno ainda pouco explorado, que se refere à diminuição do número de trabalhadores com deficiência empregados, segundo os dados da RAIS (Relação Anual das Informações Sociais) ${ }^{13}$ (BRASIL, 2008).

\footnotetext{
12 Foram utilizados Dados do IBGE que englobam toda a população - e não só das pessoas com deficiência. Utilizou-se este critério por dois motivos: em primeiro lugar, no sentido da inclusão, para verificar a questão da igualdade ou desigualdade de remuneração e oportunidades entre os trabalhadores. Além disso, os dados divulgados pelo IBGE relativos ao rendimento das pessoas com deficiência, não são exclusivos de remuneração por carteira assinada - como os apresentados na Figura 7 - incluindo, portanto, rendimentos informais e Beneficio da Prestação Continuada.

${ }^{13}$ A Relação Anual de Informações Sociais (RAIS) visa suprir as necessidades de controle da atividade trabalhista no País, o provimento de dados para a elaboração de estatísticas do trabalho e a disponibilização de informações do mercado de trabalho às entidades governamentais. Os dados constituem insumos para diversas ações de Governo como a Concessão de Benefícios Previdenciários. A disponibilização desses dados pelo MTE objetiva estimular o debate sobre esses temas, com vistas ao desenvolvimento de diagnósticos e elaboração de políticas para propiciar iguais oportunidades de inserção dos trabalhadores no mercado de trabalho e, por conseguinte, contribuir para a redução das desigualdades socioeconômicas existentes. Informações disponíveis no site http:/ / www.mte.gov.br/rais/oquee.asp. Acesso em: 23 jan. 2010.
} 
As informações da RAIS (BRASIL, 2008) registraram em 2008 a existência de 323,2 mil empregos declarados como portadores de necessidades especiais ${ }^{14}$ no mercado de trabalho formal. Este número representou em torno de 0,8\% do contingente de empregos, cujo montante chegou a 39,4 milhões de vínculos no ano em análise. Significa, tanto em valores absolutos como em percentual, um ligeiro recuo em relação aos dados verificados em 2007 (348.818 pessoas com deficiência empregadas no Brasil, cerca de 0,9\% dos 37,6 milhões de vínculos). Ainda em comparação aos dados deste mesmo instrumento, no ano 2000, dos 26 milhões de trabalhadores formais ativos apenas 537 mil eram pessoas com deficiência, representando 2,05\% deste total. Assim, mesmo que grandes esforços venham se fazendo na área da inclusão, ao que parece, os dados apresentados neste estudo, em parte, contribuem para o entendimento no que se refere à carência de resultados efetivos na empregabilidade dos trabalhadores deficientes.

Tabela 2 - Ocupação dos Funcionários com Deficiência (em \%)

\begin{tabular}{l|cccccccccccccc}
\hline $\begin{array}{l}\text { Tipo de } \\
\text { Ocupação }\end{array}$ & A & B & C & D & E & F & G & H & I & J & K & L & M & N \\
\hline $\begin{array}{l}\text { Frequência } \\
\text { (em \%) }\end{array}$ & 48,9 & 31,6 & 6,7 & 3,7 & 2,5 & 1,5 & 1 & 0,8 & 0,8 & 0,6 & 0,6 & 0,6 & 0,4 & 0,4 \\
\hline
\end{tabular}

Fonte: Dados obtidos na Organização ${ }^{15}$

No que se refere à função ou ocupação desenvolvida pelos funcionários com deficiência empregados na organização ora analisada, a Tabela 2 nos demonstra em termos percentuais a concentração das atividades desses sujeitos.

A função A, que concentra quase a metade dos funcionários empregados $(48,9 \%)$, segundo a descrição de seu ofício, é basicamente composta de tarefas que envolvem limpeza, organização, carregamento e descarregamento ${ }^{16}$. A função B, com 31,6\% dos cargos, ainda que tenha algumas atividades relacionadas à organização, já apresenta algumas atividades de conferência, definindo um pouco mais de responsabilidade à função. Mas tem entre suas atribuições muitas obrigações semelhantes à função A.

Funções gerenciais, de coordenação ou supervisão, são identificadas na soma de duas atividades (J e K), totalizando cerca de 1,2\% das ocupações. Desta forma, evidencia-se uma relação muito estreita entre este cenário e os dados já apresentados, no que se refere à escolaridade e remuneração deste estrato populacional da empresa analisada.

\footnotetext{
14 Termo utilizado pelo Ministério do Trabalho e Emprego.

${ }^{15}$ Os nomes das Ocupações foram ocultados para impedir a identificação da Organização. Tal informação é dispensável para a análise proposta neste estudo.

${ }^{16}$ Optou-se por uma descrição genérica das ocupações que permita ao leitor compreender essência das atividades laborais sem a identificação da Organização.
} 
Não se espera que indivíduos sem a devida formação educacional, $a$ priori, ocupem cargos nos altos escalões de qualquer instituição, cujos expertises têm sido valorados de forma muito significativa. É, portanto, compreensível que todos esses elementos estejam tão imbricados e tão alinhados em seu resultado. A educação ainda parece ser uma carência social muito importante para esta parcela da população.

Corroborando esta afirmativa, o Centro Regional de Informações das Nações Unidas afirma que, segundo a UNESCO, nos países em desenvolvimento cerca de $90 \%$ das crianças com deficiência não frequentam a escola. Além disso, estudo do Programa das Nações Unidas para o Desenvolvimento (PNUD, 2010) revelou que a taxa de alfabetização mundial relativa aos adultos com deficiência não excede os 3\% e, particularmente, no caso das mulheres com deficiência, este índice alcança apenas $1 \%$.

Assim, embora esta análise não se esgote neste estudo, nestes dados podemos perceber um pouco da difícil equação social para a inclusão de pessoas com deficiência no mercado de trabalho. Naturalmente não se tem a pretensão de afirmar que estes dados correspondem à realidade de todas as empresas brasileiras, mas, em se tratando de uma grande empresa cuja natureza da atividade demanda uma grande quantidade de mão-de-obra, percebe-se que ainda há grandes obstáculos para que a inclusão no mercado de trabalho efetivamente se realize.

\section{Conclusões}

A análise do perfil das pessoas com deficiência inseridas no mercado de trabalho, através dos dados de uma Organização de grande porte, nos conduziu a diversas reflexões sobre este processo. Inicialmente, considerando a política de inclusão de deficientes no mercado de trabalho, enquanto uma política ou norma pública a ser cumprida por uma organização privada, deve-se salientar o seu mérito. É inegável o avanço que tais medidas representam na história do trabalho da pessoa com deficiência e sobre a vida e o trabalho de muitas pessoas com deficiência. Estes mesmos atribuem à Lei as transformações positivas de suas vidas.

Contudo, do ponto de vista das empresas o cumprimento da Lei de Cotas enfrenta uma série de resistências. A difícil relação que se estabelece entre produtividade e responsabilidade social ainda não obteve respostas ou resultados satisfatórios para nenhuma das partes envolvidas neste processo. Costa (2008) refere a importância de a Lei de Cotas estar acompanhada de medidas que não só estimulem mas também criem condições para as organizações contratarem e manterem em seus quadros as pessoas com deficiência. $\mathrm{O}$ autor acrescenta que "as pesquisas mostram que as pessoas se tornam mais sensíveis à contratação na medida em que acumulam boas experiências com os portadores de deficiência" (COSTA, 2008, p. 109).

Ainda no processo de reflexão, outro problema que tem sido abordado socialmente, e também foi trazido ao debate no decorrer da pesquisa, foi a influência 
do Benefício Previdenciário no processo de inclusão do mercado de trabalho. $\mathrm{O}$ Benefício Previdenciário parece ser um importante elemento na complexidade de fatores que envolvem a contratação de pessoas com deficiência nas organizações.

Segundo Nascimento, Bahia e Cunha (2007), em que pese o BPC ter representado um beneficio às pessoas com deficiência em situação de exclusão e pobreza - o que justifica o amparo do Estado -, a sua existência representa uma barreira significativa ao próprio processo de inclusão, pelo menos para as pessoas com baixa qualificação profissional,

[...] a quem a alternativa de emprego formal pode significar remuneração idêntica
ou muito próxima ao valor do benefício assistencial e assim não compensar o risco
de trocar o que é líquido e certo para toda a vida (o recebimento do BPC) pelo du-
vidoso (a perspectiva de passar a ser assalariado, situação que está sujeita ao risco
de não-continuidade) (NASCIMENTO; BAHIA; CUNHA, 2007, p. 3).

Esta análise que compara a dificuldade de contratar empregados com deficiência em função do Beneficio da Prestação Continuada é realizada constantemente pelos gestores de Recursos Humanos da empresa, embora não se possa afirmar que o BPC seja o real motivador da carência de mão de obra.

Através da análise já apresentada pelos dados apresentados neste artigo, fica clara também a dura realidade enfrentada pelas pessoas com deficiência. Um baixo índice de pessoas tem escolaridade de nível superior - apenas 5\% dos funcionários têm ensino superior completo. Ora, se a escolaridade mínima é essencial para a contratação, o é também para a remuneração. Logo, o reduzido salário resultante da baixa qualificação nos conduz a uma realidade que já faz parte do conhecimento dos funcionários de Recursos Humanos que lidam com inclusão no mercado de trabalho: à medida que a Lei do Benefício Previdenciário (BRASIL, 1993) é um direito que se extingue com o trabalho, é preferível às pessoas com deficiência permanecerem na segurança de seu lar, com o direito garantido, a arriscar este direito frequentando um ambiente de trabalho incerto - aos olhos deste sujeito.

É importante salientar que não há juízo de valor ou crítica nesta constatação, ao contrário. Ao se considerarem as dificuldades sociais que a pessoa com deficiência passa ao longo de sua vida - discriminação social, dificuldade de acesso e participação nas instâncias sociais e, muitas vezes, dificuldades econômicas por conta do custo da deficiência - esta opção não só é compreensível como também razoável. Além disso, há dificuldades no encaminhamento da legislação que também devem ser levadas em conta. Caso ocorra a demissão do empregado com deficiência, apesar de ser possível a recuperação do Benefício, este processo não é automático, e ainda recai sobre ele toda a burocracia inerente a problemas desta natureza ${ }^{17}$.

17 Referir a mudança da lei em 2011 
O exercício laboral também traz custos financeiros e dificuldades reais ao cidadão com deficiência - a locomoção ainda é um problema na grande maioria das cidades brasileiras e objeto de relato frequente entre as pessoas com deficiência (IBDD, 2003).

Assim, quando se levanta o BPC como um empecilho à contratação de pessoas com deficiência, se quer apenas apontar para o problema sem ajuizar menos valor a esta conquista social de indubitável mérito destes sujeitos. O que se pretende é, de posse desta análise, convidar os órgãos competentes a um grande esforço de ajuste, para que nem os indivíduos, nem as empresas, percebam o benefício como negativo. O grande risco que se corre é justamente este, um deslocamento do conceito real e original do Benefício, como uma conquista inquestionável das pessoas com deficiência.

Por fim, a constatação não menos importante diz respeito à falta de escolaridade e de mão-de-obra, que tem sido reiteradamente apontada por diferentes autores como um dos principais entraves à contratação de deficientes (NASCIMENTO; MIRANDA, 2007; ARAÚJO; SCHMIDT, 2006; SASSAKI, 2006; TANAKA; MANZINI, 2005; VIGOLO, 2005; GÖDKE, 2010). A falta da escolaridade revelou-se, também em nossa pesquisa, um fator determinante para a inclusão das pessoas com deficiência. Se não fosse assim, porque seria tão baixa a relação de pessoas com deficiência entre as ocupações de maior responsabilidade e remuneração? Aqui cabe um maior interesse dos governantes para esta situação que ainda é crítica. Ainda se faz muito pouco pela qualificação e inclusão efetiva das pessoas com deficiência.

Em decisão recente, a desembargadora do Tribunal Regional do Trabalho em São Paulo pontua justamente este tema, destacando-o ao reverter multa estipulada a uma empresa. Segundo o acórdão, devido à natureza da atividade de certas organizações, algumas deficiências inviabilizam a adequação da pessoa com deficiência à função. E acrescenta a importância de "respeitar o tipo de deficiência em relação ao trabalho que será realizado. A capacitação profissional é degrau obrigatório do processo de inserção social”" (BRASIL, 2010).

Mais importante que isso, destacado no texto deste mesmo acórdão, não é o risco financeiro de a lei não ser cumprida, mas o risco de a lei desviar o processo de inclusão de seu curso original,

[...] que é o de trazer o portador de deficiência ao convívio social, como uma pessoa produtiva, igual às demais, desenvolvendo seus talentos, aptidões, habilidades, com efeitos benéficos em sua autoestima, e não de retirá-lo do convívio familiar, para que cumpra horário de trabalho sem função alguma (BRASIL, 2010).

Nosso entendimento, portanto, é que embora seja urgente a educação e qualificação das pessoas com deficiência, isto apenas não é suficiente, pois não basta que se qualifiquem os deficientes - problema recorrente apontado nesta e em outras pesquisas - se as organizações e a própria sociedade também não o fizerem. É preciso educar a empresa para a inclusão, enquanto não se estabelecer esta meta 
as organizações ainda verão a lei de cotas como um problema intransponível ou uma arbitrariedade das políticas públicas.

Por fim, percebe-se o quanto a sociedade ainda precisa pensar verdadeiramente a diversidade humana no sentido mais profundo. Somente assim poderemos viver numa sociedade verdadeiramente inclusiva.

\section{REFERÊNCIAS}

ARAÚJO, J.; SCHMIDT, A. A inclusão de Pessoas com Necessidades Especiais no Trabalho: A visão de empresas e instituições educacionais na cidade de Curitiba. Revista Brasileira de Educação Especial, Marília, v. 12 n. 2, p. 241-254, 2006.

BRASIL. Comitê de Ajudas Técnicas, Secretaria Especial dos Direitos Humanos da Presidência da República (CORDE/SEDH/PR). Ata da Reunião VII, de dezembro de 2007. Disponível em: <http:/ / www.mj.gov.br/ corde/ arquivos/ doc/ Ata_VII_ Reunião_do_Comite_de_Ajudas_Técnicas.doc> Acesso em: 05 jan. 2011.

. Decreto $\mathrm{n}^{\mathrm{o}} 5.296$ de 2004. Regulamenta as Leis $\mathrm{n}^{\circ} \mathrm{s} 10.048$, de 8 de novembro de 2000, que dá prioridade de atendimento às pessoas que especifica, e 10.098, de 19 de dezembro de 2000, que estabelece normas gerais e critérios básicos para a promoção da acessibilidade das pessoas portadoras de deficiência ou com mobilidade reduzida, e dá outras providências. 2004b. Disponível em: <http://www6.senado.gov.br/legislacao/ ListaPublicacoes. action?id=240147>. Acesso em: 22 fev. 2010.

. Lei no 8.213 de 1991. Dispõe sobre os Planos de Benefícios da Previdência Social e dá outras providências. Legislação brasileira sobre pessoas portadoras de deficiência. Brasília: Câmara dos deputados, Coordenação de Publicações, p. 55-58. 2004 a.

. Lei no 8.742 de 1993. Dispõe Sobre a Organização da Assistência Social e dá outras providências.. Disponível em: <http://www81.dataprev.gov.br/ sislex/ paginas/42/ 1993/ 8742. htm>. Acesso em: 22 fev. 2010.

. Lei no 9.394 de 1996. Estabelece as Diretrizes e Bases da Educação Nacional. Legislação brasileira sobre pessoas portadoras de deficiência. Brasília: Câmara dos deputados, Coordenação de Publicações, p. 55-58. 2004c.

BRASIL. Ministério do Trabalho e Emprego. Características do Emprego Formal segundo a Relação Anual de Informações Sociais, 2008. Disponível em: <http:/ / www.mte.gov.br/ pdet/ arquivos_download/rais/ resultado_2008.pdf>. Acesso em: 22 fev. 2010.

. Tribunal Regional do Trabalho. Acórdão. Ministério do Trabalho e OMINT.

Relatora: Desembargadora Rita Silvestre. 30 de agosto de 2010. In: Consultor Jurídico. Disponível em: <http:/ / www.conjur.com.br/2010-set-06/decisao-ve-retrocessoexigencia-cotas-deficientes-empresas>. Acesso em: 7 jan. 2011.

BIRD. El Banco Mundial urge a atacar La pobreza en discapacitados. Banco Mundial, 2004. Disponível em: <http://go.worldbank.org/Y7DIYDLKS0>. Acesso em: 12 nov. 2010.

COSTA, S. M. Dignidade humana e pessoa com deficiência: aspectos legais e trabalhistas. São Paulo: LTr, 2008.

FLICK, U. Introdução à pesquisa qualitativa. 3. ed. Porto Alegre: Artmed, 2009. 
FREITAS, M. T. A abordagem Sócio-histórica como orientadora da pesquisa qualitativa. Cadernos de Pesquisa, São Paulo, n.116, p.21 - 39, 2002.

GIL, A. C. Métodos e Técnicas de Pesquisa Social. 5. ed. São Paulo: Atlas, 2007.

GÖDKE, F. A inclusão excludente dos trabalhadores com deficiência nos processos produtivos industriais. 2010. 173 f. Tese (Doutorado em Educação) - Setor de Educação, Universidade Federal do Paraná, Curitiba, 2010.

GOFFMAN, E. Estigma: notas sobre a manipulação da identidade deteriorada. 4. ed. Rio de Janeiro: LTC, 1988.

IBDD. Sem Limite: inclusão de portadores de deficiência no mercado de trabalho. Rio de Janeiro: Editora Senac Rio, 2003. 144p.

IBGE. Instituto Brasileiro de Geografia e Estatística. Censo Demográfico 2000:

Características gerais da população. Rio de Janeiro, 2000. Disponível em: <http://www. ibge.gov.br/home/estatistica/populacao/censo2000/populacao/censo2000_populacao. pdf>.Acesso em: 10 set. 2010.

LANCILLOTTI, S. S. Deficiência e trabalho: redimensionando o singular no contexto universal. Campinas: Autores Associados, 2003. 111p.

MARCONI, M. A.; LAKATOS, M. Técnicas de pesquisa. 3. ed. São Paulo: Atlas, 1996.231p.

MENDONÇA. L. E. A. Lei de Cotas: pessoas com Deficiência: a visão empresarial. São Paulo: LTr, 2010. 240 p.

NASCIMENTO, E. S.; MIRANDA, T. G. O trabalho e a profissionalização das pessoas com deficiência. Revista da FACED, Salvador, v.12, n.12, 2007. p. 169 - 184.

NASCIMENTO, P. A. M.; BAHIA, M. S.; CUNHA, M. A. O Benefício de Prestação Continuada como Entrave à Inclusão da Pessoa com Deficiência no Mercado Formal de Trabalho: uma Proposta de Modificação da Lei n. ${ }^{\circ}$ 8.742/93 (LOAS). In: CONFERÊNCIA REGIONAL DE ISTR PARA AMÉRICA LATINA Y EL CARIBE, 6., 2007, Salvador. Anais... Salvador: ISTR y CIAGS/UFBA, 2007. Disponível em: <http://new. lasociedadcivil.org/docs/ciberteca/018.pdf>. Acesso em: 3 nov. 2010.

NERI, M. et al. Retratos da Deficiência no Brasil (PPD): sumários Executivos. Rio de Janeiro: FGV, IBRE, CPS, 2003. 250p.

OLIVEIRA, M. A.; GOULART JUNIOR, E.; FERNANDES, J. M. Pessoas com deficiência no mercado de trabalho: considerações sobre políticas públicas nos Estados Unidos, União Européia e Brasil. Revista Brasileira de Educação Especial, Marília, v.15, n.2, p.219-232, 2009.

PASTORE, J. Oportunidade de trabalho para portadores de deficiência. São Paulo: LTr, 2000. 245p.

PROGRAMA DAS NAÇÕES PARA O DESENVOLVIMENTO HUMANO (PNUD). Relatório de Desenvolvimento Humano 2010. New York, Colorcraft of Virginia, 2010. Disponível em: <http://hdr.undp.org/en/media/HDR_2010_PT_Complete.pdf>. Acesso em: 14 dez. 2010.

SANTOS, M. P. Perspectiva Histórica do movimento integracionista na Europa. Revista Brasileira de Educação Especial, São Carlos, v.2, 1995. Acesso em: 15 jan. 2011.

SANTOS, W. R. Deficiência e BPC: o que muda na vida das pessoas atendidas? Revista Ciência e Saúde Coletiva [online]. v. 16, supl. 1. p. 787-796, 2011. Disponível em http:/ / 
www.scielosp.org/scielo.php?script=sci_arttext\&pid=S1413-81232011000700009\&lng=pt \&nrm=iso\&tlng=pt. Acesso em: 16 nov. 2010.

SASSAKI, R. K. Inclusão: Construindo uma sociedade para todos. 7. ed. Rio de Janeiro: WVA, 2006.

TANAKA, E. D. O.; MANZINI, E. J. O que os empregadores pensam sobre o trabalho da pessoa com deficiência? Revista Brasileira de Educação Especial [online], Marília, v. 11 n. 2, p. 273-294, 2005. Acesso em: 24 jan. 2010.

VIGOLO, A. Um olhar sobre as representações das pessoas com necessidades especiais e o mundo do trabalho. São Leopoldo: UNISINOS, 2005. Monografia (Especialização em Educação Especial). Universidade do Vale do Rio dos Sinos, 2005.

Recebido em: 16/06/2011

Reformulado em: 03/02/2012

Aprovado em: 30/03/2012 